\title{
Extraction of DNA staining dyes from DNA using hydrophobic ionic liquids
}

\author{
Imran Khimji, Krystina Doan, Kiara Bruggeman, Po-Jung Jimmy Huang, Puja Vajha, and Juewen Liu* \\ Received 21st February 2013, Accepted 4th April 2013 \\ DOI: 10.1039/C3CC41364K
}

The partition of oligonucleotides and DNA staining dyes into a few hydrophobic ionic liquids has been studied, where the oligonucleotides remain in the aqueous phase and all the DNA staining dyes are extracted in the ionic liquid phase, allowing 10 the separation of these two.

DNA staining dyes are commonly used in molecular biology and analytical chemistry for detecting not only nucleic acids, but also metal ions, small molecules and proteins (e.g. with DNA aptamers). ${ }^{1-6}$ Most DNA staining dyes are conjugated 15 cationic molecules and they bind to DNA via electrostatic, $\pi$ $\pi$ stacking and intercalation interactions to produce strong fluorescence. The DNA/dye complex is very stable and can often survive gel electrophoresis. Therefore, one of the analytical challenges is to remove the dye after staining so 20 that precious DNA samples might still be used for other applications. So far, no attempts have been reported to achieve this goal.

Ionic liquids (ILs) are molten salts at around room temperature. ${ }^{7-10}$ ILs are comprised of cations and anions with 25 low symmetry, disfavoring their packing into stable crystals. With very low vapor pressure, ILs are considered to be green solvents that may replace some of the conventional organic solvents. Recently, ILs have been shown to dissolve many biopolymers. ${ }^{11-14}$ Some protein enzymes are more stable and 30 active in ILs. ${ }^{15}$ ILs can also provide long-term stability to DNA. ${ }^{16}$ Various studies have been carried out to understand the interaction between ILs and DNA. ${ }^{17-22}$

There are two types of ILs; one type is hydrophilic and miscible with water while the other type is hydrophobic and 35 forms a separate phase in water. We recently reported that some hydrophilic ILs can either act as salt to increase the melting temperature $\left(T_{\mathrm{m}}\right)$ of DNA or as solvent to reduce its $T_{\mathrm{m}}{ }^{22}$ Hydrophobic ILs, on the other hand, might be used for analyte enrichment and extraction. ${ }^{23-25}$ Hydrophobic ILs have 40 also been used for DNA separation, ${ }^{26}$ translocation, ${ }^{27}$ mass spectrometry, ${ }^{28}$ and DNA gel fiber formation. ${ }^{29}$ We reason that hydrophobic ILs might interact with DNA staining dyes via electrostatic, hydrophobic and van der Waals interactions, which may be stronger than its interaction with DNA. In this 45 work, we demonstrate extraction of DNA staining dye from DNA using hydrophobic ILs.

A total of four ILs were studied in this work (Figure 1A). $\left[\right.$ Emim] $\left[\mathrm{PF}_{6}\right]$ is a solid at room temperature with poor water solubility. [Bmim] $\left[\mathrm{PF}_{6}\right]$ and $[\mathrm{Hmim}]\left[\mathrm{PF}_{6}\right]$ are liquids and 50 show phase separation with water, while $[\mathrm{Bmim}]\left[\mathrm{BF}_{4}\right]$ is miscible with water. As an initial test, we mixed a 24-mer single-stranded (ss) DNA with SYBR Green I dye (SG) in buffer (50 mM NaCl, $20 \mathrm{mM}$ HEPES, pH 7.6). A strong green fluorescence was observed under UV excitation (Figure 1B).

${ }_{55} \mathrm{We}$ then added an equal volume of $[\mathrm{Bmim}]\left[\mathrm{PF}_{6}\right]$. After a thorough mixing and then centrifugation to facilitate phase separation, the fluorescence disappeared. This suggests that the DNA and SG either are separated into different phases or are both extracted into the IL phase, where the fluorescence 60 was quenched.

To confirm the location of DNA, we repeated the experiment with a Cy3-labeled DNA (Figure 1C). The DNA alone fluoresced orange and addition of $\mathrm{SG}$ resulted in stronger fluorescence due to the staining of the DNA. After ${ }_{65}$ mixing with $[\mathrm{Bmim}]\left[\mathrm{PF}_{6}\right]$, no fluorescence was observed in the bottom IL layer while the upper aqueous layer remained orange. Therefore, the DNA was likely in the upper aqueous phase and SG was extracted into the IL phase.

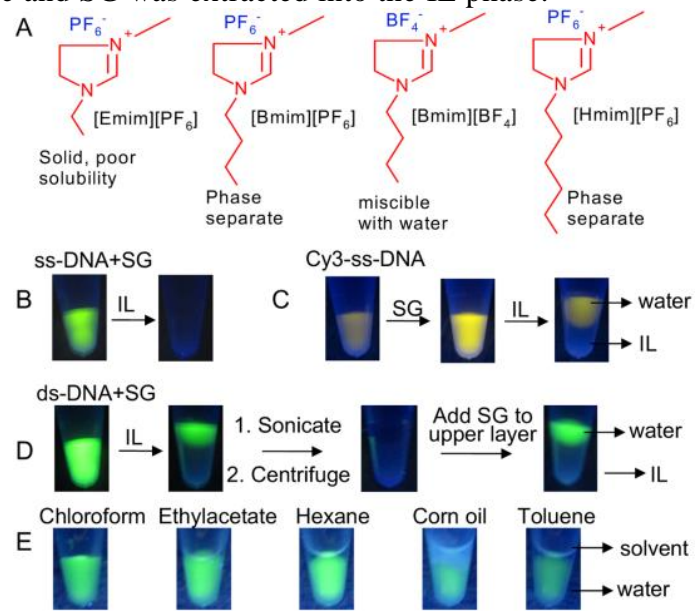

70 Figure 1. (A) Structures of the ILs used in this work. Fluorescence photographs of partition of non-labeled ss-24-mer DNA (B), ss-Cy3-DNA $(\mathrm{C})$, and non-labeled ds-24-mer DNA (D) in water/[Bmim] $\left[\mathrm{PF}_{6}\right]$ mixture. The aqueous layer is on the top since this $\mathrm{IL}$ is heavier than water. (E) Partition of ds-24-mer DNA/SG in water/molecular solvent mixtures. The 75 aqueous layers are at the bottom due to higher density.

Since ss-DNA has very low affinity for SG, we next tested ds-DNA. The cDNA of the 24-mer DNA was added to form a duplex, where SG generated a highly fluorescent sample 
(Figure 1D). Addition of SG and vortex resulted in the upper aqueous layer to be green fluorescent and the lower IL layer to be dark, suggesting that both the ds-DNA and SG were in the aqueous phase, consistent with the high affinity between 5 ds-DNA and SG. For comparison, the fluorescence disappeared if ss-DNA was used (Figure 1B). We next sonicated the sample to facilitate mixing, where a milky emulsion like mixture was obtained. After centrifugation, the sample showed phase separation again but became completely 10 dark. Addition of more SG to the aqueous phase regained fluorescence. Therefore, at least a fraction of the DNA remained in the aqueous phase, while the dye has been extracted into the IL phase. The extraction of the dye out of the aqueous phase cannot be achieved by molecular solvents 15 (Figure 1E). Among the five tested solvents, none separated the DNA/SG complex since fluorescence was observed for all the samples in the aqueous phases.

To explore the generality of our observation, we tested a few more DNA staining dyes including ethidium bromide 20 (EB), SYTO-13, PicoGreen and thiazole orange (TO). The dsDNA/dye complexes were respectively mixed with two types of ILs (Figure 2A). In all cases, the upper aqueous layers were non-fluorescent but weak fluorescence was observed in the lower IL phases. Gentle addition of the dyes into the aqueous 25 phases resulted in strong fluorescence for EB and PicoGreen but SYTO-13 and TO still showed weak fluorescence even without sonication (Figure 2B), suggesting that either these dyes have very strong affinity for the ILs or relatively weaker affinity for the DNA.

30 For comparison, the dyes themselves without DNA were tested (Figure 2C); the dyes appeared to be in the bottom IL phases and the fluorescence property was similar to that in Figure 2A. This confirms that the ILs could extract the dyes regardless of the presence or absence of DNA. It is interesting 35 to note that the fluorescence of the dyes were stronger in the ILs than that in water when no DNA was present, suggesting that the dyes might have similar interactions with the ILs as that achieved with DNA to promote their fluorescence. Since most DNA staining dyes are cationic, to have a general 40 understanding, we also tested a few anionic dyes, which can also be extracted into the ILs and be protonated (Figure S1, ESI). However, deoxyadenosine cannot be extracted (Figure S2). It appears that hydrophobicity and charge are important to determine extraction efficiency by ILs.

45 In the above work, we used a volume ratio of 1:1 between the aqueous phase and the IL phase. To test the efficiency of extraction, we fixed the concentrations of the ds-DNA (100 $\mathrm{nM})$ and dye $(1 \mu \mathrm{M})$ with the total sample volume of $200 \mu \mathrm{L}$. Next, various volumes of IL were added. After mixing and 50 phase separation, the fluorescence in the aqueous phase was measured and complete dye extraction indicated by the lost of fluorescence was achieved with just $10 \mu \mathrm{L}$ [Bmim][PF6] (5\%) (Figure $3 \mathrm{~A}$ ) or $5 \mu \mathrm{L}[\mathrm{Hmim}]\left[\mathrm{PF}_{6}\right]$ (Figure $3 \mathrm{~B}$ ). We did not test even lower IL volumes since $[\mathrm{Bmim}]\left[\mathrm{PF}_{6}\right]$ has a solubility 55 of $2 \%$ in water. ${ }^{30,31}$ The slightly higher extraction efficiency of $[\mathrm{Hmim}]\left[\mathrm{PF}_{6}\right]$ might be related to its even lower solubility in water. Such high extraction efficiency was observed for SG, TO, and EB, confirming the generality.
Our work also indicated that at least a fraction of DNA 60 (Figure 1C, D) remained in the aqueous phase, allowing DNA separation with the dyes that are extracted into the ILs. Next, we aim to quantitatively test the partition of DNA. We employed FAM-labeled homopolymers (15-mer) of all the nucleotides. After thorough mixing and phase separation, the 65 aqueous phase fluorescence was measured (Figure 3C). The DNA fluorescence in the aqueous phase remained quite constant for all the DNA sequences, suggesting that most of the DNA should still be in the aqueous phase. Since this observation is different from a published paper, ${ }^{25}$ we 70 performed back extraction (Figure 3D). The aqueous phase after mixing with IL shows roughly the same fluorescence intensity compared to the original DNA dispersed just in water (red and blue bars in Figure 3D). For back extraction, the IL phase was carefully transferred to a new tube and water 75 or an extraction buffer was added. Based on back extraction, the amount of DNA extracted into the IL phase was less than $5 \%$ and this is true for all the tested DNA homopolymers (Figure 3D, blue and purple bars). Therefore, it is unlikely that these ILs can be used for DNA extraction. On the other 80 hand, as we demonstrated above, they are ideal for extraction of DNA staining dyes.

In the paper where DNA extraction was reported, long dsDNA was used while we used oligonucleotides in this study. To make a full comparison, we also tested such long DNA. ${ }_{85}$ Using the EB staining assay described in the paper, ${ }^{25}$ some DNA extraction was suggested with certain buffer conditions based on fluorescence decrease. However, no extraction was found based on back extraction. We also developed a UV-vis based assay to quantify DNA at $260 \mathrm{~nm}$, where no DNA 90 extraction was observed either. We reason that this reported 'extraction' of DNA might be related to artifacts associated with ILs and dye interaction and also to the very low DNA concentration used (Figure S3-7, ESI). We also measured that even single nucleosides tend to stay in the aqueous phase 95 (Figure S2). Overall, our studies indicate that DNA cannot be extracted by the ILs tested in this paper. It needs to be noted that by changing the design of ILs, it is possible to selectively extract DNA. ${ }^{32}$

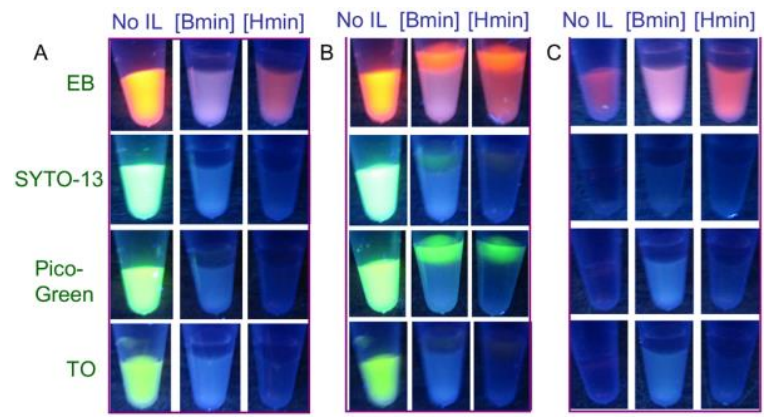

100 Figure 2. Fluorescence photographs of (A) extraction of ds-DNA/dye mixtures by ILs; (B) add dyes to the upper aqueous layer to the samples from (A); (C) extraction of the dyes (no DNA) by the ILs. The bottom layers are the ILs and the top layers are water.

Since these ILs still have certain solubility in water, the 105 dissolved IL might affect the property of DNA in the aqueous phase. For example, $[\mathrm{Bmim}]\left[\mathrm{PF}_{6}\right]$ has $2 \%$ solubility in water, ${ }^{30}$ which translates into $\sim 70 \mathrm{mM}$ IL. After extraction, 
we need test whether the property of DNA is affected by the extraction process. One assay for such effects is to measure the $T_{\mathrm{m}}$ of DNA. For this purpose, we thoroughly mixed an aqueous buffer with $\left[\mathrm{Bmim}^{\mathrm{mim}}\left[\mathrm{PF}_{6}\right]\right.$ and harvested the aqueous 5 phase with saturated IL. Compared to the normal aqueous buffer, the $T_{\mathrm{m}}$ increased by just $1{ }^{\circ} \mathrm{C}$. For comparison, when $\mathrm{NaCl}$ was added to the same DNA, the $T_{\mathrm{m}}$ value increased from $37{ }^{\circ} \mathrm{C}$ to $63{ }^{\circ} \mathrm{C}$. The same measurement was also performed using $[\mathrm{Bmin}]\left[\mathrm{BF}_{4}\right]$, which is miscible with water. 10 The DNA reached the highest $T_{\mathrm{m}}$ of $43{ }^{\circ} \mathrm{C}$ at $\sim 100 \mathrm{mM}$ IL and further increase of the $[\mathrm{Bmin}]\left[\mathrm{BF}_{4}\right]$ concentration suppressed $T_{\mathrm{m}}$. DNA destabilization at high IL concentration is likely due to the hydrophobic interaction between the IL and DNA base, weakening DNA base pairing interactions. Therefore, these 15 hydrophobic ILs at low concentration are ineffective salts for promoting the DNA duplex stability, likely due to their bulky cation sizes. We further tested the extracted DNA for PCR, where they can also be amplified similar to the orginal untreated DNA (Figure S8). Therefore, for the two 20 hydrophobic ILs we tested, they did not affect the stability of the DNA significantly.
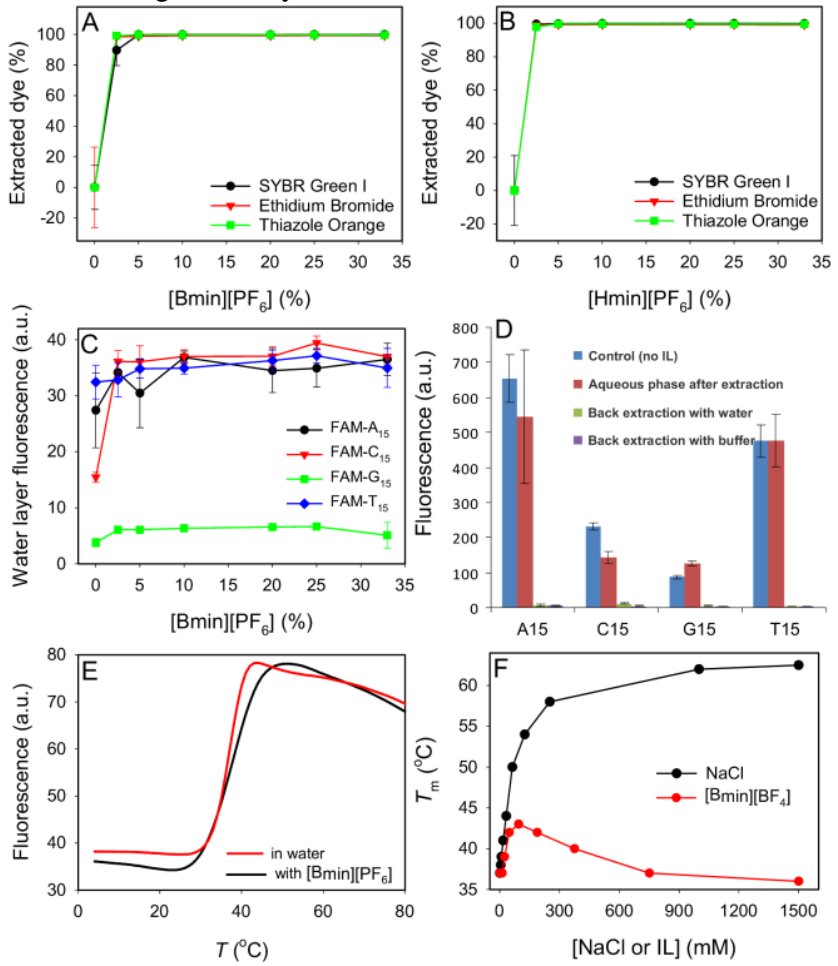

Figure 3. Extraction efficiency of various dyes by $[\mathrm{Bmim}]\left[\mathrm{PF}_{6}\right](\mathrm{A})$ and by $[\mathrm{Hmim}]\left[\mathrm{PF}_{6}\right](\mathrm{B})$. (C) Fluorescence intensity of the aqueous phase ${ }_{25} \mathrm{DNA}$ as a function of $[\mathrm{Bmim}]\left[\mathrm{PF}_{6}\right]$ concentration after extraction. The lack of fluorescence drop indicates that DNA was still in the aqueous phase. (D) Back extraction into aqueous buffer confirming the lack of DNA in the IL phase. (E) Melting curves of a DNA duplex in aqueous buffer and in the buffer with saturated $[\mathrm{Bmim}]\left[\mathrm{PF}_{6}\right]$. $(\mathrm{F}) T_{\mathrm{m}}$ as a function 30 of $\mathrm{NaCl}$ or $[\mathrm{Bmim}]\left[\mathrm{BF}_{4}\right]$ concentration of the ds-DNA.

In summary, we have reported a method to efficiently separate DNA staining dyes from DNA without disturbing DNA properties. We found that DNA remained in the aqueous phase instead of in the IL phase. Finally, the affinity between 35 ILs and DNA staining dyes is very strong and care needs to be taken for assays involving ILs and these dyes to quantify
DNA.

Funding for this work is from the University of Waterloo, the Canadian Foundation for Innovation, and the NSERC of ${ }_{40}$ Canada. J. Liu received an Early Researcher Award from the Ontario Ministry of Research and Innovation.

\section{Notes and references}

Department of Chemistry, Waterloo Institute for Nanotechnology,

University of Waterloo, Waterloo, Ontario, N2L 3G1, Canada. Fax: 519 45 7460435; Tel: 5198884567 Ext.38919; E-mail: liujw@ uwaterloo.ca

Electronic supplementary information (ESI) available. See DOI:

1 B. A. D. Neto and A. A. M. Lapis, Molecules, 2009, 14, 1725.

2 Y. Jiang, X. Fang and C. Bai, Anal. Chem., 2004, 76, 5230.

503 T. Li, S. Dong and E. Wang, J. Am. Chem. Soc., 2010, 132, 13156.

4 C. W. Liu, C. C. Huang and H. T. Chang, Anal. Chem., 2009, 81, 2383.

5 Y. Xiang, A. J. Tong and Y. Lu, J. Am. Chem. Soc., 2009, 131, 15352.

556 J. Wang and B. Liu, Chem. Comm., 2008, 4759.

7 T. Welton, Chem. Rev., 1999, 99, 2071.

8 M. Armand, F. Endres, D. R. MacFarlane, H. Ohno and B. Scrosati, Nat. Mater., 2009, 8, 621.

9 M. J. Earle and K. R. Seddon, Pure Appl. Chem., 2000, 72, 1391.

6010 Z. Jin, D.-X. Xie, X.-B. Zhang, Y.-J. Gong and W. Tan, Anal. Chem., 2012, 84, 4253.

11 L. Cardoso and N. M. Micaelo, ChemPhysChem, 2011, 12, 275.

12 I. Mamajanov, A. E. Engelhart, H. D. Bean and N. V. Hud, Angew. Chem. Int. Ed., 2010, 49, 6310.

6513 N. Nishimura, Y. Nomura, N. Nakamura and H. Ohno, Biomaterials, 2005, 26, 5558.

14 X. B. Lu, J. Q. Hu, X. Yao, Z. P. Wang and J. H. Li, Biomacromolecules, 2006, 7, 975.

15 M. Moniruzzaman, K. Nakashima, N. Kamiya and M. Goto, $70 \quad$ Biochem. Eng. J., 2010, 48, 295.

16 R. Vijayaraghavan, A. Izgorodin, V. Ganesh, M. Surianarayanan and D. R. MacFarlane, Angew. Chem. Int. Ed., 2010, 49, 1631.

17 D. H. Cheng, X. W. Chen, J. H. Wang and Z. L. Fang, Chem. Eur. J., 2007, 13, 4833.

7518 Y. H. Ding, L. Zhang, J. Xie and R. Guo, J. Phys. Chem. B, 2010, 114, 2033.

19 Y. N. Xie, S. F. Wang, Z. L. Zhang and D. W. Pang, J. Phys. Chem. $B, 2008, \mathbf{1 1 2}, 9864$.

20 H. Y. Wang, J. J. Wang and S. B. Zhang, Phys. Chem. Chem. Phys., 2011, 13, 3906

21 H. Tateishi-Karimata and N. Sugimoto, Angew. Chem., Int. Ed., 2012, 51, 1416

22 A. Beg Menhaj, B. Smith and J. Liu, Chem. Sci., 2012, 3, 3216.

23 X. Han and D. W. Armstrong, Acc. Chem. Res., 2007, 40, 1079.

8524 P. Sun and D. W. Armstrong, Anal. Chim. Acta, 2010, 661, 1.

25 J. H. Wang, D. H. Cheng, X. W. Chen, Z. Du and Z. L. Fang, Anal. Chem., 2007, 79, 620.

26 W. D. Qin and S. F. Y. Li, Analyst, 2003, 128, 37.

27 R. S. S. de Zoysa, D. A. Jayawardhana, Q. Zhao, D. Wang, D. W.

$90 \quad$ Armstrong and X. Guan, J. Phys. Chem. B, 2009, 113, 13332.

28 S. Carda-Broch, A. Berthod and D. W. Armstrong, Rapid Commun. Mass Sp., 2003, 17, 553.

29 C. K. Lee, S. R. Shin, S. H. Lee, J. H. Jeon, I. So, T. M. Kang, S. I Kim, J. Y. Mun, S. S. Han, G. M. Spinks, G. G. Wallace and S. J.

95 Kim, Angew. Chem. Int. Ed., 2008, 47, 2470.

30 M. G. Freire, C. M. S. S. Neves, P. J. Carvalho, R. L. Gardas, A. M. Fernandes, I. M. Marrucho, L. s. M. N. B. F. Santos and J. o. A. P. Coutinho, J. Phys. Chem. B, 2007, 111, 13082.

31 R. P. Swatloski, A. E. Visser, W. M. Reichert, G. A. Broker, L. M. 100 Farina, J. D. Holbrey and R. D. Rogers, Green Chem., 2002, 4, 81.

32 T. Li, M. D. Joshi, D. R. Ronning and J. L. Anderson, J. Chromatogr. A, 2013, 1272, 8. 